\title{
BIOMIMETIC CONTROL OF AUTONOMOUS UNDERWATER VEHICLES: A MODELLING ALGORYTHM FOR COMPUTING THE CURRENT SWAY
}

\author{
Octavian TARABUTA ${ }^{1}$ \\ Gheorghe ICHIMOAEI ${ }^{2}$ \\ Catalin-Paul CLINCI ${ }^{3}$ \\ Aurel GHERGHINA ${ }^{4}$ \\ ${ }^{1}$ Assoc. Prof. PhD, "Mircea cel Batran" Naval Academy, Constanta, Romania
${ }^{2}$ Advanced Instructor, PhD, "Mircea cel Batran" Naval Academy, Constanta, Romania
${ }^{3}$ Lecturer PhD, "Mircea cel Batran" Naval Academy, Constanta, Romania
${ }^{4} \mathrm{PhD}$, Ministry of National Defence, Bucharest, Romania
}

Abstract: The sway produced by the sea currents on autonomous underwater vehicles (AUV) is an unpredictable variable that impedes them to follow a straight course, as desired. In order to correct these errors, the authors previously proposed a biomimetic approach of control, by determining the influences of sea currents through an array of pressure sensors on both sides of the AUV, resembling a fish's lateral line. The values of the incidences and intensities of the current pushing the AUV can be measured by the lateral line array as differences in the pressures of two corresponding points on both sides of the AUV. Subsequently, the micro-controller in charge with motion control has to correct the disturbed trajectory after analyzing the input error. This paper describes an algorithm for transforming the pressure differences from the sensors to empirical mathematical equations that can describe the current parameters, thus allowing the controller to command the proper corrective action to the propulsion motors.

Keywords: AUV, biomimetic, current, sway, controller

\section{Introduction.}

Accurate guidance of AUV on a desired course over long distances is a major problem standing in front of the control subsystem's designers. The main cause of the errors in keeping the AUV's straight course while on an underwater trajectory is the sea currents. This constant input force on the hydrodynamic array of forces and moments acting on the AUV cannot be predicted before the run. The current influence on the AUV's motion is variable over the operational range of the AUV, in both horizontal but also in the vertical planes. The error applied by the sea current on the trajectory's control system has ultimately two components: speed and incidence relative to the vehicle's hull. In a previous paper, the authors asked themselves: How can we improve accuracy of control by taking into consideration the very cause of the problem, the influence of the current, rather than avoiding it? As technology doesn't use it, is there any other example from the nature that shows us any method of current correction? Indeed, we found out some answers to these questions, that we present hereby.

This is how we started to tackle a method for the underwater current correction of INS navigation system based on a biomimetic approach. Fish and aquatic mammals are using hydrodynamic reception, i.e. detection of subtle changes of water pressure around them that signal the presence of a moving body (friend or foe) within their sensorial envelope. Fish use their lateral line as a pressure sensing system, allowing them to react in changing their course for attacking pray or social schooling. By considering that the lateral line system can also explain navigation of fish during long range migrations, the authors present a study of how the differences between pressure distributions on the AUV's body can measure the speed and incidence of an underwater current hence satisfactorily trigger current corrections of INS-based AUV'sautomatic navigation systems.

1. Measuring the current influence on the AUV.

In order to extract the input given by the sea current on the AUV's motion, we have to measure the disturbance that the current produces on its body, taking also into consideration the actual operational requirements.

Obviously, if the vehicle has no self-propulsion, the current is eventually aligning the AUV in the current. The relative motion is the same as the transport motion, therefore there are no dynamic pressures acting on the hull. Yet, the AUV's compass, preset on a certain course, gives the control system the reference direction. 
"Mircea cel Batran" Naval Academy Scientific Bulletin, Volume XIX - 2016 - Issue 2

The journal is indexed in: PROQUEST / DOAJ / Crossref / EBSCOhost / INDEX COPERNICUS / DRJI / OAJI I

JOURNAL INDEX I I2OR / SCIENCE LIBRARY INDEX / Google Scholar I Academic Keys/ ROAD Open Access I

Academic Resources / Scientific Indexing Services / SCIPIO / JIFACTOR

Consequently, any error in following the reference direction is corrected by the controller which commands the propellers in order to re-establish the set course. That means that the AUV, having a constant speed through the water, also keeps the absolute bearing in a fixed reference systemunchanged. In these conditions, a given sea current will always have the same incidence relative to the AUV's body, which supposedly will produce different hydrodynamic pressures on the AUV's sides (Fig.1).
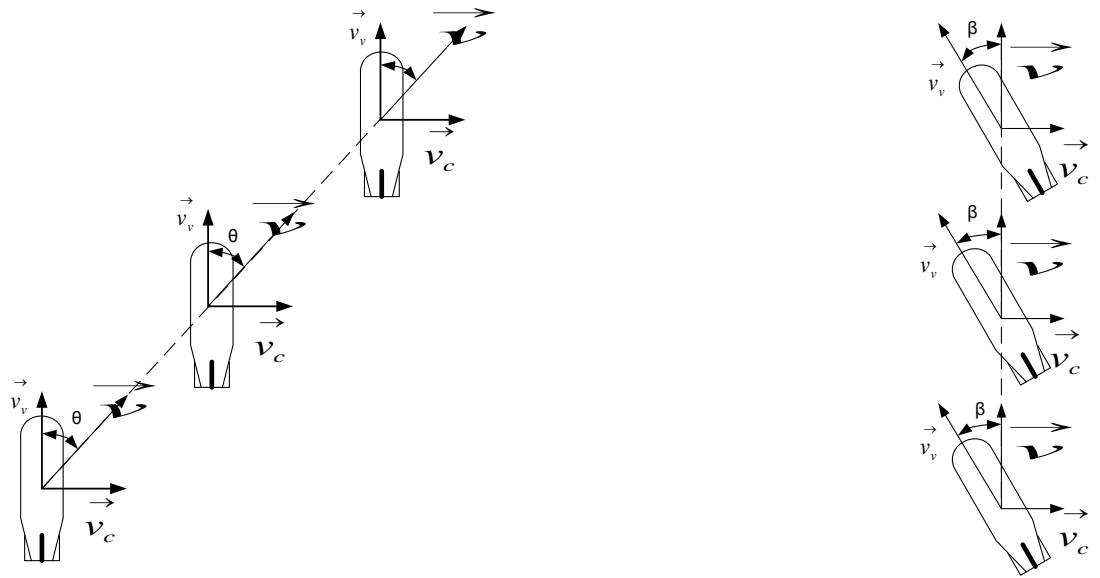

Fig.1. AUV's INS-based movement in current, without and with correction

The authors explored the pressure distributions by the means of the Ansys CFX software and reported the results. In brief, as the dynamic pressures on the hull are a result of both speeds of current and its incidences to the vehicle, the simulations were done for two situations: constant speed and variable incidence, respectively constant incidence and variable speed. This allows us to eventually draw the pressure on a given spot as a function of two variables, speed and incidence.

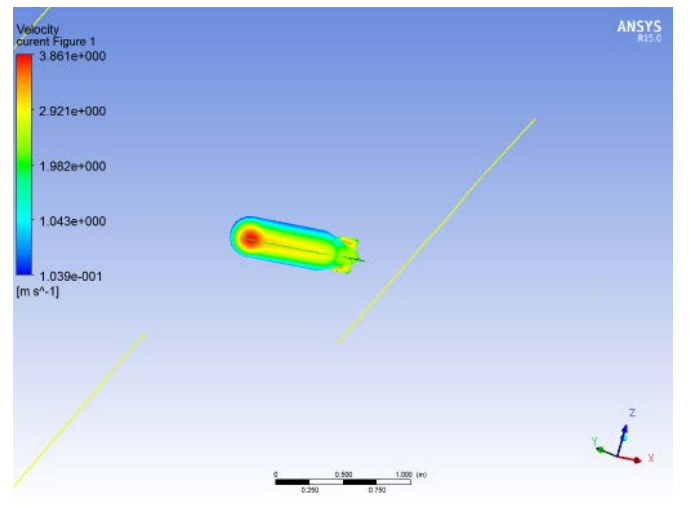

The simulations considered a series of incidence angles of $0^{\circ}, 45^{\circ}, 90^{\circ}$ and $135^{\circ}$. The values of speed are between 1.5 and $3.0 \mathrm{~m} / \mathrm{s}$. Other initial conditions are water temperature $25^{\circ} \mathrm{C}$ and a turbulent flow. The pressures are measured in the port and starboard sides, in the horizontal plane (AUV's equator).

A sample of the results of the previous simulations is presented in the figure below.

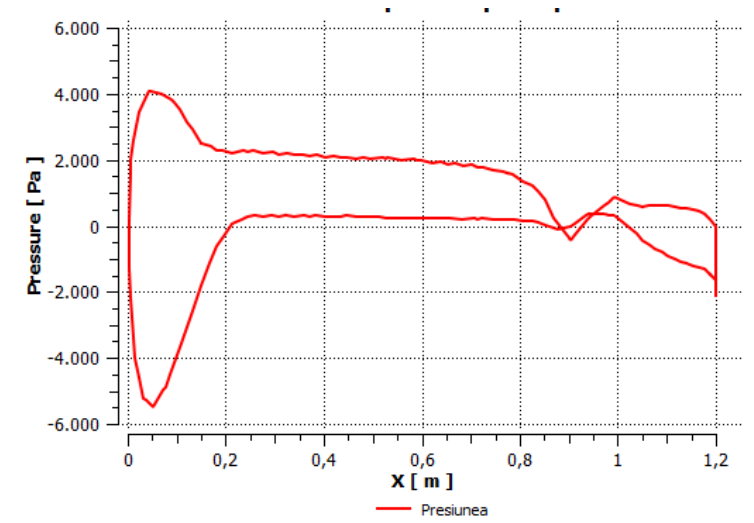

Fig.2. Pressure distributions on port and starboard sides ( $45^{\circ}$ of incidence). 
"Mircea cel Batran" Naval Academy Scientific Bulletin, Volume XIX - 2016 - Issue 2

The journal is indexed in: PROQUEST / DOAJ / Crossref / EBSCOhost / INDEX COPERNICUS / DRJI / OAJI I JOURNAL INDEX I I2OR / SCIENCE LIBRARY INDEX / Google Scholar I Academic Keys/ ROAD Open Access I Academic Resources / Scientific Indexing Services / SCIPIO / JIFACTOR
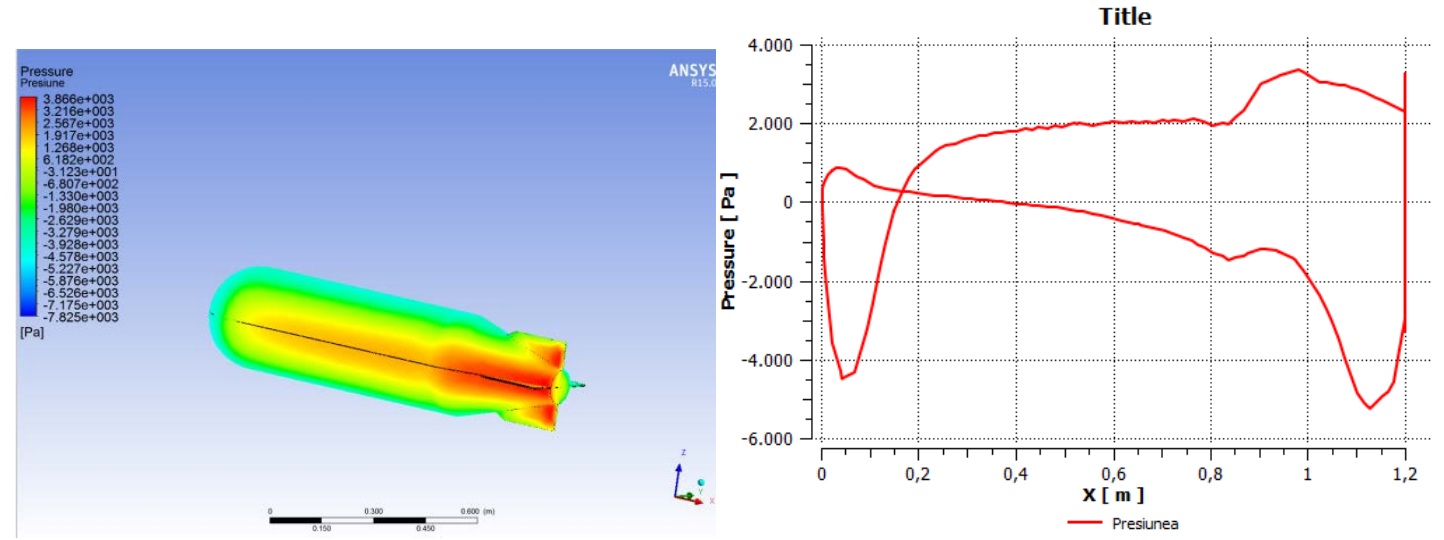

Fig.3. Pressure distributions $\left(135^{\circ}\right.$ of incidence)

2. Designing the theoretical fundamentals of the correction algorithm.

From the study of the simulation results one can observe that, indeed, the action of current on the AUV that keeps its longitudinal axis parallel to itself determines different distribution curves on port and starboard side. The differences are not very big - in the order of Pascals - but still measurable with appropriate sensors.

On the other hand, the profile of pressures is identical in shape for constant incidences, or for constant speeds. This will allow stepping forward onto the problem of recognition of these diagrams and the differences between pressures on two symmetrical points located on the same meridian.

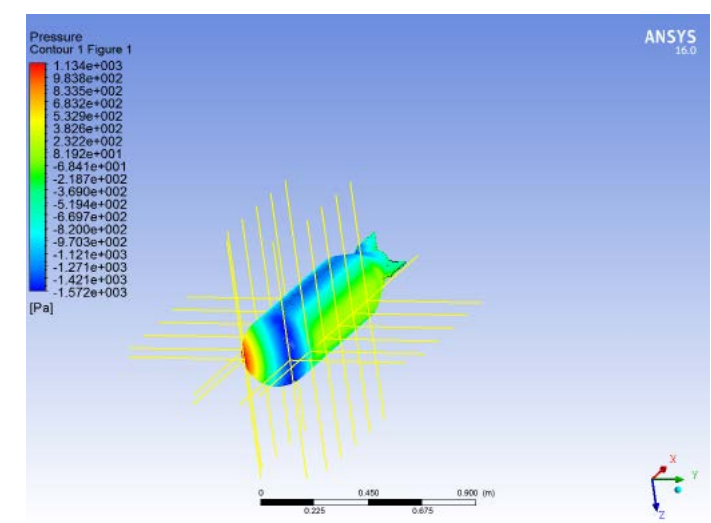

As the sensors are able to differentiate between two side pressures on the same meridian of the hull, a programme for the AUV's controller can be further developed. In the end, information from the pressure sensors along the AUV can be processed in order to command the gyrocompass not to keep the absolute course, but a corrected one, which will add the necessary yaw to it.

Obviously, a correction algorithm will be based on mathematical functions able to be uploaded in and recognized by the processor. The authors determined further the theoretical difference functions by the means of Ansys CFX simulation, as well.

The measuring points grid is presented in Fig.4.

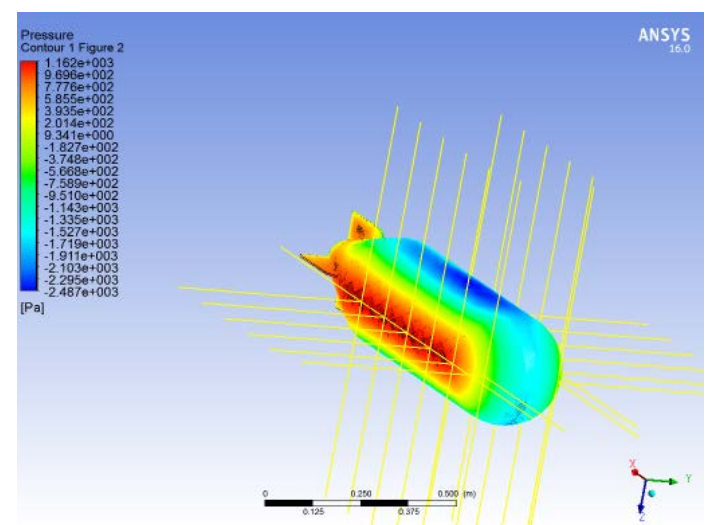

\begin{tabular}{|l|l|l|l|l|l|l|}
\hline X (mm) & 44 & 150 & 300 & 450 & 600 & 750 \\
\hline Y Td (mm) & 10,6 & 150 & 150 & 150 & 150 & 150 \\
\hline Y Bd (mm) & $-10,6$ & -150 & -150 & -150 & -150 & -150 \\
\hline$Z(m m)$ & 0 & 0 & 0 & 0 & 0 & 0 \\
\hline
\end{tabular}

Fig.4. The measuring grid for incidence of $45^{\circ}$ and $90^{\circ}$ 
"Mircea cel Batran" Naval Academy Scientific Bulletin, Volume XIX - 2016 - Issue 2 The journal is indexed in: PROQUEST / DOAJ / Crossref / EBSCOhost / INDEX COPERNICUS / DRJI / OAJI / JOURNAL INDEX I I2OR / SCIENCE LIBRARY INDEX / Google Scholar / Academic Keys/ ROAD Open Access I Academic Resources / Scientific Indexing Services / SCIPIO / JIFACTOR

The diagrams of the differences between 2 points on the same meridian are depicted below.


DOI: 10.21279/1454-864X-16-12-016

(C) 2015. This work is licensed under the Creative Commons Attribution-Noncommercial-Share Alike 4.0 License. 
"Mircea cel Batran" Naval Academy Scientific Bulletin, Volume XIX - 2016 - Issue 2

The journal is indexed in: PROQUEST / DOAJ / Crossref / EBSCOhost / INDEX COPERNICUS / DRJI / OAJI I JOURNAL INDEX I I2OR / SCIENCE LIBRARY INDEX / Google Scholar / Academic Keys/ ROAD Open Access I Academic Resources / Scientific Indexing Services / SCIPIO / JIFACTOR

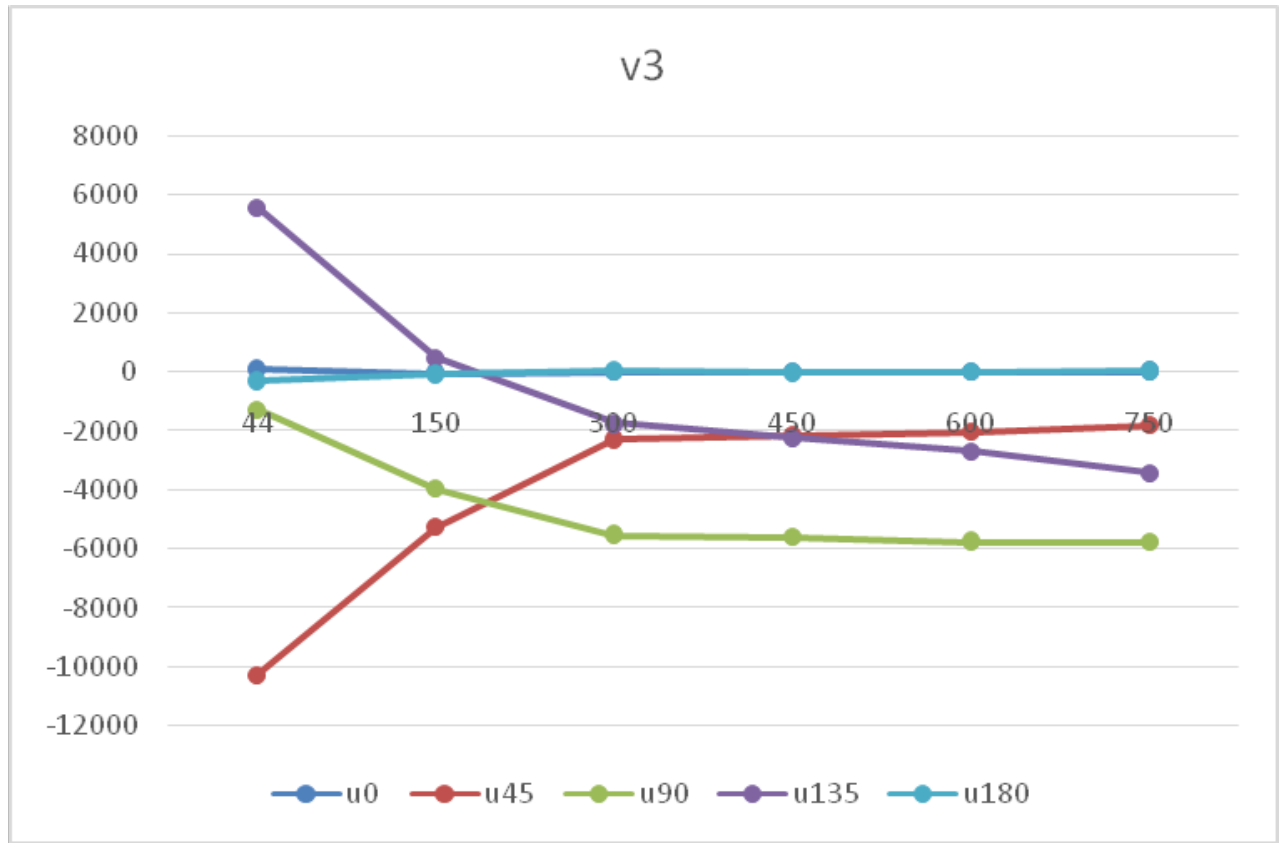

Fig.5. The computed differences for speeds of current of 1.5, 2.0 and $3.0 \mathrm{~m} / \mathrm{s}$.

From these graphs we can notice that for incidences of $0^{\circ}$ and $180^{\circ}$ the values are the same, hence the differences are nil, which we expected anyway as the AUV is symmetrical. The next step the authors carried out was finding the polynomial functions that fit the discrete values of the pressure differences. We used the FindGraph application, which basically finds the function that crosses all the coordinates empirically determined. We identified polynomial functions of the $6^{\text {th }}$ order, as described in Fig. 6 and Fig. 7 .
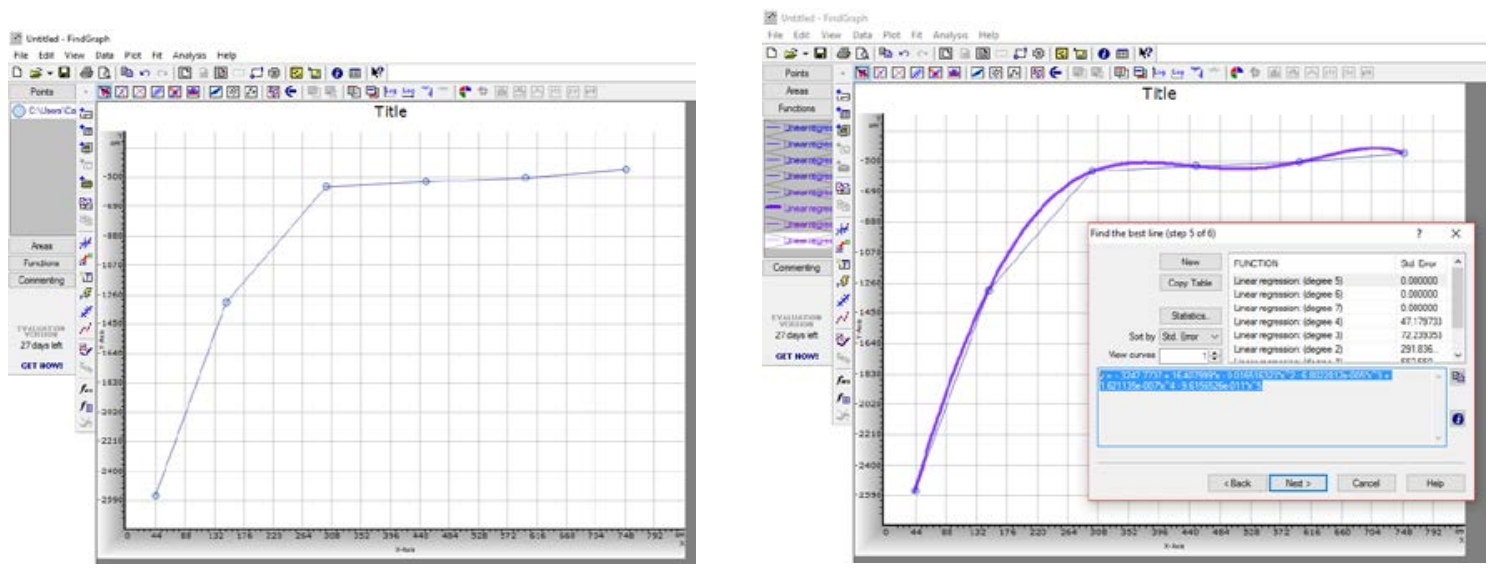

Fig.6. The polynomial function for current of speed $1.5 \mathrm{~m} / \mathrm{s}$, incidence $45^{\circ}$ 
"Mircea cel Batran" Naval Academy Scientific Bulletin, Volume XIX - 2016 - Issue 2 The journal is indexed in: PROQUEST / DOAJ / Crossref / EBSCOhost / INDEX COPERNICUS / DRJI / OAJI / JOURNAL INDEX / I2OR / SCIENCE LIBRARY INDEX / Google Scholar / Academic Keys/ ROAD Open Access I Academic Resources / Scientific Indexing Services / SCIPIO / JIFACTOR


Fig.7. The polynomial function for current of speed $1.5 \mathrm{~m} / \mathrm{s}$, incidences $90^{\circ}$ and $135^{\circ}$

The polynomial functions determined have the following forms:

$y=-3247.7737+16.407999^{\star} x-0.016516323^{\star} x^{\wedge} 2-6.8022812 e-005^{\star} x^{\wedge} 3+1.621135 e-007^{\star} x^{\wedge} 4-$ $9.6156526 \mathrm{e}-011 * x^{\wedge} 5(\mathbf{u} 45)$

$y=-488.65652+7.0979937^{\star} x-0.1030436^{\star} x^{\wedge} 2+0.00036023655^{\star} x^{\wedge} 3-5.0435963 e-007^{\star} x^{\wedge} 4+$ $2.4983885 e-010 * x^{\wedge} 5($ u90)

$y=209.90387+7.4247967 * x-0.0886969{ }^{\star} x^{\wedge} 2+0.00028803252^{\star} x^{\wedge} 3-3.8520892 e-007^{\star} x^{\wedge} 4+1.8382399 e-$ $010 * x^{\wedge} 5(\mathbf{u} 135)$

\section{CONCLUSIONS}

In conclusion, having these functions, we can use these algorithms necessary for the controller in order to transform inversely the differences of pressures into speed and angle of incidence of the sea current that has to be corrected.

Further experimental validation of the theoretical model will be needed, yet the authors are quite confident that the results of the simulations and the polynomial approach of the functions of differences will be useful for the sway correction of an AUV.

\section{BIBLIOGRAPHY}

[1] M. Sfakiotakis, D.M. Lane, J.B.c. Davies, J.B.c. "An Experimental undulating-fin deviceusingtheparallel Bellows Actuator." Proc. of the 2001 IEEE Int. Conf. on Robotics and Automation, Seoul, Korea, May 21-25, 2001, pp. 2356-2362.

[2] Andres Punning, Mart Anton, Maarja Kruusmaa, Alvo Aabloo, "A Biologically Inspired Ray-likeUnderwater Robot with Electroactive Polymer Pectoral Fins", Proc. of the Int. IEEE Conf. Mechatronics and Robotics 2004 (MechRob'04), Vol. 2, pp. 241 - 245, 13. - 15. Sept. 2004, Aachen.

[3] R.L. Wernli. "AUVs - A Technology Whose Time Has Come.", 2002. Proceedings of the 2002 International Symposium on Underwater Technology, 16-19 April 2002, pp. 309-314.

[4] S. Liu, D.Wang, E.K.Poh, "A Nonlinear Observer For AUVs in Shallow Water Environment." Proceedings of the 2004 IEEE/RJS Int. Conf. on Intelligent Robots and Systems (IROS 2004), Sept. 28 - Oct. 2, 2004 , Sendai, Japan, pp. 1130-1135.

[5] J.Yuh, "Design and Control of AutonomousUnderwaterRobots: A Survey." Autonomous Robots, Vol. 8, 2000, pp. 7- 24. 